\title{
Conflitos com o paciente, cor/raça e concepçóes de estudantes de Odontologia: uma análise com graduandos no Sul do Brasil
}

\author{
I ${ }^{1}$ Laise Cordeiro Candido, ${ }^{2}$ Mirelle Finkler, ${ }^{3}$ João Luiz Bastos, \\ ${ }^{4}$ Sérgio Fernando Torres de Freitas I
}

Resumo: Os processos sócio-históricos ocorridos no Brasil resultaram em desigualdades de saúde entre diferentes grupos étnico-raciais. A fim de investigar tais desigualdades na Odontologia, este estudo buscou avaliar se concepções de seus graduandos variam em função da cor/raça de um paciente, quando confrontados com a discordância dele e a necessidade de identificar fatores responsáveis pelo insucesso do tratamento. Os dados foram coletados com um questionário autopreenchível, respondido por 166 alunos matriculados em um curso de Odontologia no Sul do Brasil. Apresentou-se um caso clínico hipotético aos estudantes em dois momentos distintos: no primeiro, o paciente foi caracterizado com a cor negra; no segundo, branca. Os casos demandavam tratamento de um problema dental idêntico, após o qual foram aplicadas perguntas abertas, cujas respostas foram examinadas por meio da Análise de Conteúdo Temática. Os resultados sugerem um comportamento menos respeitoso e menos autonomia dada ao paciente negro em relação ao branco. Os pacientes negros também foram mais responsabilizados por falhas no tratamento, quando comparados a seus pares brancos. Com base nesses resultados, sugerimos que a formação dos profissionais de saúde se concentre no tema das desigualdades raciais, para melhor equipá-los para a construção de uma sociedade menos desigual.

> Palavras-chave: serviços de saúde; educação profissional; graduação; saúde bucal.

\author{
1 Universidade Federal de Santa \\ Catarina. Florianópolis-SC, Brasil \\ (laise_cord@hotmail.com) \\ ORCID: 0000-0003-0662-7624 \\ ${ }^{2}$ Universidade Federal de Santa \\ Catarina. Florianópolis-SC, Brasil \\ (mirellefinkler@yahoo.com.br). \\ ORCID: 0000-0001-5764-9183. \\ ${ }^{3}$ Universidade Federal de Santa \\ Catarina. Florianópolis-SC, Brasil \\ (joao.luiz.epi@gmail.com). \\ ORCID: 0000-0002-1816-0745. \\ ${ }^{4}$ Universidade Federal de Santa \\ Catarina. Florianópolis-SC, Brasil \\ (sergio.freitas@ufsc.br). \\ ORCID: 0000-0002-8904-5998.
}

Recebido em: 27/03/2019 Revisado em: 12/07/2019 Aprovado em: 24/07/2019 


\section{Introdução}

A formação da sociedade brasileira foi baseada em uma estrutura colonial e racista, que esteve vinculada a um processo de objetificação de milhóes de negros e os submeteu a condiçóes subumanas de vida e trabalho (TELLES, 2004). A Abolição da Escravatura, desacompanhada de medidas de inclusão da população liberta, substituiu o escravismo pelo trabalho livre de maneira excludente, mantendo ou mesmo aprofundando as condiçôes de marginalização e exclusão desse segmento populacional no país (TELLES, 2016). Por outro lado, determinados grupos de imigrantes europeus receberam diferentes aportes financeiros e sociais por parte do Estado para residir no Brasil, permitindo-os ocupar uma posição privilegiada na escala social, tanto em termos absolutos quanto relativos (SEYFERTH, 2002).

A literatura que evidencia as desigualdades enfrentadas pela população negra brasileira é especialmente vasta. Setenta e oito por cento do décimo mais pobre do Brasil são formados por pretos ou pardos, enquanto quase $80 \%$ dos $1 \%$ mais ricos da população é branca (IBGE, 2016). A média anual do rendimento do trabalhador negro - termo que se refere à agregação das categorias censitárias de pretos e pardos - é cerca de 40\% menor do que a do trabalhador branco (IBGE, 2016). No âmbito da saúde, também são observadas desigualdades raciais expressivas. Enquanto 85\% das gestantes brancas passam por, pelo menos, seis consultas pré-natais, este valor cai para 69\% quando se trata das negras (BRASIL, 2016). Homens negros, por sua vez, são os que mais morrem por causas externas: dos 30 mil jovens de 15 a 24 anos assassinados em 2012, 77\% eram pretos ou pardos, embora eles constituam pouco menos de metade da população masculina do país (DONATO, 2014).

Tal cenário de marcantes desigualdades também se reproduz na Odontologia e na prestação de cuidados em saúde bucal. Em particular, a pesquisa na área tem repetidamente apontado que:

1) grupos socialmente marginalizados, incluindo os negros, apresentam maiores frequências de agravos, doenças bucais ou piores condiçôes de tratamento;

2) a magnitude dessas iniquidades é expressiva e persistente no espaço-tempo; e

3) as desigualdades raciais são apenas parcialmente explicadas pela desvantagem socioeconômica de alguns segmentos da população relativamente a outros (BASTOS; CELESTE; PARADIES, 2018). 
No âmbito da formação, estudantes de Odontologia lidam, já em seus primeiros contatos com usuários nas clínicas de ensino, com uma variada gama de problemas éticos, que abrangem desde o privilégio no atendimento de pessoas próximas até o não fornecimento de informaçôes aos pacientes sobre a realização de procedimentos terapêuticos (GONÇALVES; VERDI, 2007). Atravessados por conflitos éticos desde a sua formação e inseridos num contexto mais amplo de racismo, os profissionais de Odontologia expressam, não raro, comportamentos que sugerem pouca reflexão sobre questôes raciais e que, portanto, discriminam determinados segmentos da população. Investigação prévia demonstrou que, em um cenário clínico de total igualdade de condiçóes entre os pacientes, cirurgiôesdentistas atuando profissionalmente em Recife, Nordeste do Brasil, recomendaram a extração dentária em maior frequência para os usuários negros do que para os brancos (CABRAL; CALDAS; CABRAL, 2005).

Outras investigaçóes de natureza semelhante têm sugerido que estudantes de Odontologia apresentam dificuldade para relativizar situaçóes conflituosas, privilegiando o interesse pessoal, quando suscitados a resolver dilemas de cunho moral (FREITAS et al., 2006; FREITAS; KOVALESKI; BOING, 2005). Entre os aspectos discutidos nessas pesquisas, destaca-se a dificuldade de o curso de graduação promover uma formação pautada por princípios éticos e de valorização da vida. Argumenta-se que cirurgióes-dentistas que orientam suas decisóes profissionais por questóes como a busca de recompensa e a valorização da própria reputação podem oferecer cuidados de pior qualidade a seus pacientes e, em especial, a determinados grupos. Nesse sentido, a formação essencialmente técnica e pouco voltada para problemas definidos no campo das ciências humanas e sociais, entre eles o racismo, pode contribuir para que cirurgiôesdentistas baseiem suas decisóes clínicas em ideias preconcebidas e equivocadas sobre grupos sociais (CABRAL; CALDAS; CABRAL, 2005).

Objetivando explorar questôes relativas às interfaces entre ética, racismo e formação/atuação em Odontologia, um estudo foi recentemente realizado para verificar se a cor/raça de u m paciente hipotético influencia a tomada de decisôes clínicas relacionadas com o tratamento de um elemento dental extensamente cariado. Seu resultado principal demonstrou não haver diferenças estatisticamente significativas nas condutas clínicas indicadas pelos estudantes, conforme a caracterização étnicoracial dos pacientes (SCHROEDER et al., 2017). Tal constatação motivou, assim, os coordenadores da pesquisa a analisar outras dimensóes do cuidado abordadas 
na coleta de dados, aprofundando a discussão das eventuais desigualdades de tratamento entre pacientes brancos e negros. O presente trabalho buscou, então, avaliar que concepçóes os estudantes de Odontologia acionam quando confrontados com a discordância do paciente e a necessidade de identificação de responsáveis pelo insucesso de um tratamento clínico. Adotando uma perspectiva teórica particular da bioética, bem como uma estratégia metodológica distinta do estudo anterior (SCHROEDER et al., 2017), procura-se analisar aqui se tais concepçóes estão relacionadas com a caracterização étnico-racial dos casos clínicos apresentados.

Parte-se do princípio de que o respeito à autonomia dos indivíduos deve ser preservado, conforme previamente discutido no Relatório Belmont (THE NATIONAL COMMISSION..., 1979). Segundo esse documento, o respeito à autonomia deve ser tomado como um dos mais importantes princípios morais, podendo ser descrito de um modo prático como segue:

To respect autonomy is to give weight to autonomous persons' considered opinions and choices while refraining from obstructing their actions unless they are clearly detrimental to others [...] Respect for persons requires that subjects, to the degree that they are capable, be given the opportunity to choose what shall or shall not happen to them.

Em oposiçáo ao respeito à autonomia está o que se tem denominado em bioética de paternalismo, o qual entende que é o profissional de saúde que pode e deve dizer o que é benéfico ao paciente, e não ele próprio. Portanto, uma conduta paternalista é aquela que busca o bem do paciente, independentemente de seus valores ou opiniōes, podendo prescindir do diálogo e da deliberação com o mesmo (GRACIA, 2004). É a partir destes conceitos de autonomia e paternalismo que as respostas dos estudantes frente às situações enunciadas acima serão analisadas.

\section{Métodos}

O presente estudo analisa dados coletados em uma pesquisa com estudantes de Odontologia, realizada em 2015 e 2016 (SCHROEDER et al., 2017), que incluiu dois momentos de coleta de dados junto aos participantes - este aspecto do estudo está discutido em mais detalhes logo abaixo. Tais estudantes haviam sido aprovados ou estavam cursando disciplinas cujos conteúdos são relacionados aos temas tratados no questionário utilizado na pesquisa. Foram excluídos da investigação os estudantes que possuíam conhecimento prévio do projeto; participaram do estudo-piloto; 
estavam em atividades de intercâmbio; haviam solicitado transferência para outras instituiçóes; ou estavam com a matrícula suspensa no período de coleta de dados. Com isso, 262 estudantes elegíveis foram convidados a participar.

O questionário aplicado ao conjunto da referida amostra foi eletrônico e autopreenchível. Após solicitar informaçôes de caracterização socioeconômica dos respondentes, este apresentava um caso clínico hipotético, acompanhado de dados de anamnese e cinco fotografias. A vinheta descrevia um paciente com 31 anos de idade, com a profissão de vendedor, solteiro, com renda familiar média de R \$ 1.540, não fumante, não consumidor de álcool, com alta atividade de cárie, em bom estado de saúde geral e tendo como queixa principal a dor no elemento dental ilustrado nas imagens. Todas as ilustraçôes se referiam a um dente anterior extensamente acometido por cárie, cujo tratamento clínico poderia envolver desde sua: (1) manutenção em boca, através de procedimentos restauradores; até a (2) extração, com posterior indicação para implante ou procedimentos protéticos. As fotografias destacavam o terço inferior da face do paciente, as arcadas dentárias superior e inferior (omitindose os lábios), o elemento dental acometido por cárie e uma radiografia periapical recurso diagnóstico auxiliar na escolha do tratamento a ser recomendado.

Após a apresentação do caso clínico hipotético, o questionário convidava os respondentes a se concentrar em outros dois blocos de questôes referentes à decisão clínica; enquanto o primeiro incluía perguntas para os que tivessem recomendado a extração do elemento dental, o segundo se dirigia aos estudantes cuja opção tivesse sido sua restauração. O questionário se encerrava, então, com duas perguntas abertas que simulavam situaçóes conflituosas que potencialmente emergem na interação com os pacientes. A primeira lidava com a discordância do paciente frente ao tratamento proposto, estando circunscrita ao período prévio à intervenção clínica. Por sua vez, a segunda ilustrava uma condição de insucesso de tratamento, posteriormente à realização do procedimento clínico indicado. As perguntas tiveram a seguinte redação: (1) "Considerando que o paciente não concordou com a opção de tratamento que você escolheu para o elemento dental em questão, como você procederia? Escreva uma justificativa breve e clara sobre a sua resposta"; e (2) "Finalizado o tratamento do elemento dental (extraçáo ou restauração), considere que o paciente voltou para uma consulta de acompanhamento após alguns meses. Nesta consulta, observa-se fracasso no tratamento. Na sua opinião, quem é o principal responsável pelo insucesso do tratamento? Escreva uma justificativa breve e clara sobre a sua resposta”. 
Na primeira ocasião de contato com os respondentes, o caso clínico apresentado se referiu a um paciente caracterizado com a cor/raça preta. Passado um período mínimo de dois meses (tempo considerado na literatura (CABRAL; CALDAS; CABRAL, 2005) como suficiente para evitar contaminação de respostas em coletas seriadas de dados), os participantes foram contatados novamente para a avaliação de caso clínico idêntico em todos os aspectos, exceto por sua caracterização de cor/raça. Neste segundo momento, o paciente tinha cor/raça branca e os mesmos conjuntos de perguntas do questionário original - relativas às condutas clínicas, à discordância do paciente e ao insucesso do tratamento - foram novamente respondidos. Esse processo permitiu comparar as respostas dadas sobre o paciente preto com aquelas fornecidas para o paciente branco sem que qualquer outro fator diferisse entre os dois períodos de coleta de dados. Com efeito, ao serem sondados sobre os objetivos do trabalho ao término do segundo momento de coleta de dados, os respondentes citaram aspectos relacionados à adequada indicação de técnicas restauradoras ou cirúrgicas para os casos analisados, não havendo qualquer menção de que a cor/raça dos pacientes era o foco primordial da iniciativa de pesquisa.

Foram analisadas, no presente estudo, as respostas a ambas as perguntas abertas enunciadas acima, extraindo seus núcleos de sentido principais, ou seja, palavras ou expressôes representativas do conteúdo central, transformando-os em códigos. Estes, por sua vez, foram agrupados e reagrupados em categorias em função de suas temáticas, conforme preconiza a Análise de Conteúdo Temática (MINAYO, 2014). A análise das respostas à primeira pergunta se pautou pela noçáo bioética de maior ou menor respeito à autonomia do paciente. Em particular, suas respostas foram convertidas em quatro categorias: atribuiu-se o código 1 para as que representavam maior respeito à autonomia do paciente e o 4, para aquelas que sugeriam o contrário, aqui denominadas de paternalistas. Posiçóes intermediárias receberam os códigos 2, para o predomínio de autonomia ou 3, para a preponderância de paternalismo. O quadro 1 apresenta trechos de respostas típicas de cada categoria elaborada. Por sua vez, no item sobre a responsabilização pelo insucesso do tratamento clínico, as categorias emergentes referiram-se a quem ou a quais fatores os participantes atribuíam o insucesso do tratamento. Tais dados foram quantificados e analisados por meio de estatística descritiva. Houve casos de participantes que, em ambas as perguntas, não responderam ou não souberam responder. Tendo em vista que o questionário eletrônico impunha a necessidade de inserir texto para avançar para as 
questôes seguintes, alguns digitaram apenas letras aleatórias ou responderam "não sei”. Nestes casos, os respondentes foram agrupados em uma categoria à parte.

Quadro 1. Exemplos de respostas acerca de como os participantes procederiam, em caso de discordância do paciente em relação ao tratamento proposto. Florianópolis, 2017

\begin{tabular}{|l|l|}
\hline \multicolumn{1}{|c|}{ Classificaçáo } & \multicolumn{1}{c|}{ Exemplos de respostas } \\
\hline $\begin{array}{l}\text { 1. Maior autonomia e diálogo - respostas } \\
\text { que manifestavam alguma intenção em saber } \\
\text { as razóes da recusa ao tratamento indicado }\end{array}$ & $\begin{array}{l}\text { "Procuraria esclarecer a conduta clínica } \\
\text { escolhida, explanando os benefícios do } \\
\text { tratamento de forma que o paciente se sinta } \\
\text { confortável em aceitá-lo. Além de ouvir } \\
\text { a opinião e/ou sugestáo dele em relação } \\
\text { a esse tratamento ou algum outro de sua } \\
\text { preferência." }\end{array}$ \\
\hline $\begin{array}{l}\text { 2. Justificativas que consideravam outras } \\
\text { possibilidades de tratamento, mas náo } \\
\text { refletiam sobre as razóes da recusa }\end{array}$ & $\begin{array}{l}\text { "Apresentaria outras alternativas } \\
\text { disponíveis." }\end{array}$ \\
\hline $\begin{array}{l}\text { 3. Respostas que reafirmavam o tratamento } \\
\text { indicado, mas ponderavam outras } \\
\text { possibilidades }\end{array}$ & $\begin{array}{l}\text { "Tentaria convencer o paciente que aquele seria } \\
\text { o melhor tratamento a ser oferecido. Caso ele } \\
\text { náo aceite, iria pensar em outra opçáo." }\end{array}$ \\
\hline $\begin{array}{l}\text { 4. Maior paternalismo - justificativas } \\
\text { que reafirmavam o tratamento indicado, } \\
\text { excluindo qualquer alternativa }\end{array}$ & "Não há outra atitude que possa ser tomada." \\
\hline
\end{tabular}

Fonte: elaboração própria.

O projeto desta pesquisa foi aprovado pelo Comitê de Ética em Pesquisa em Seres Humanos, sob o parecer de número 711.450. Os estudantes que aceitaram participar assinaram o Termo de Consentimento Livre e Esclarecido e foram orientados quanto ao preenchimento eletrônico do questionário no laboratório de informática do curso de Odontologia investigado.

\section{Resultados}

Dos 262 estudantes elegíveis, 166 participaram da pesquisa nos dois momentos de coleta de dados e responderam ao questionário em sua totalidade. A amostra reproduziu as características da população de estudo: 72,7\% participantes do sexo 
feminino, com faixa etária predominante nos grupos 20 a $23(53,9 \%)$ e 24 a 33 anos $(46,1 \%)$, respectivamente. A maioria dos estudantes enquadrava-se entre as categorias econômicas B1 e E do critério da Associação Brasileira de Empresas de Pesquisa, que reflete poder de consumo; $89,6 \%$ se declararam brancos, quase a metade deles havia concluído o ensino fundamental em escola pública $(48,1 \%)$ e $66,1 \%$ haviam cursado o ensino médio em instituiçôes privadas de ensino. Um quarto dos entrevistados (25,7\%) acessou a universidade por meio de políticas de açôes afirmativas e 40,4\% já haviam participado de atividades universitárias extracurriculares.

Os dados da tabela 1 mostram que os estudantes atribuíram maior autonomia aos pacientes brancos (15,7\% das respostas) do que aos pacientes negros (9,0\%). Se consideramos as respostas 1 e 2 como uma abordagem mais autônoma contra as respostas 3 e 4 como uma abordagem mais paternalista, os resultados mostram, novamente, maior atribuiçáo de autonomia aos brancos $(61,4 \%)$ do que aos negros $(53,0 \%)$. Submetidos ao teste de qui-quadrado, os resultados mostraram-se muito próximos do limite de significância estatística: quando considerada apenas a resposta 1 , o valor foi $\mathrm{x} 2=3,37(\mathrm{p}=0,0655)$; quando consideradas todas as categorias, $\mathrm{x} 2=3,59$ ( $\mathrm{p}=0,0581)$. Essa discrepância foi sempre maior para as respostas mais extremas, ou seja, ocorreu um posicionamento mais evidente de autonomia aos pacientes brancos.

Tabela 1. Classificação das respostas sobre como os estudantes procederiam em caso de discordância do paciente em relação ao tratamento proposto, segundo cor/raça do paciente hipotético. Florianópolis, 2017

\begin{tabular}{lcc}
\hline \multirow{2}{*}{ Classificação } & \multicolumn{2}{c}{ Cor/raça } \\
\cline { 2 - 3 } & $\begin{array}{c}\text { Paciente negro } \\
\mathbf{N}(\%)\end{array}$ & $\begin{array}{c}\text { Paciente branco } \\
\mathbf{N}(\%)\end{array}$ \\
\hline $\begin{array}{l}\text { 1 Maior autonomia e diálogo } \\
\text { 2 Justificativas que consideravam } \\
\text { outras possibilidades de tratamento }\end{array}$ & $15(9,03)$ & $26(15,66)$ \\
$\begin{array}{l}\text { 3 Respostas que reafirmavam o } \\
\text { tratamento indicado }\end{array}$ & $39(23,50)$ & $76(45,78)$ \\
4 Maior paternalismo & $39(23,50)$ & $27(16,26)$ \\
Não soube responder & - & $32(19,28)$ \\
\hline Total & $166(100,00)$ & $166(100,00)$ \\
\hline
\end{tabular}

Fonte: elaboração própria. 
$\mathrm{Na}$ tabela 2, apresentam-se os resultados obtidos para cada categoria que emergiu na análise sobre a atribuição da responsabilidade em caso de insucesso do tratamento. As respostas mostraram que, em cerca de $10 \%$ dos casos, os estudantes não souberam responder ou não conseguiram se decidir sobre uma das categorias. Excluídas estas respostas, a responsabilidade atribuída exclusivamente ao paciente apresentou diferença significativa limítrofe entre negros e brancos $(\mathrm{x} 2=3,87$ e $\mathrm{p}=0,0493$ ), com maior responsabilização de negros. Nas respostas que se referiam ao paciente negro como responsável pelo insucesso do tratamento, destacaram-se justificativas de negligência do mesmo perante as orientaçôes e recomendaçóes profissionais. Nesse mesmo sentido, algumas respostas também citaram como explicação a não cooperação do paciente. Em menor frequência do que as anteriores, os participantes responderam somente de quem era a responsabilidade, mas sem esclarecer a razão. Com uma frequência bem reduzida, outra justificativa apontada foi associada à falta de higiene do paciente. Houve, ainda, aqueles respondentes que associaram a responsabilidade do paciente explicitamente à falta de cuidado. Alguns exemplos das justificativas aportadas de acordo com as categorias temáticas em relação ao paciente negro podem ser observadas no Quadro 2. Por sua vez, quando o caso clínico se tratava de um paciente branco, as justificativas da responsabilidade pelo insucesso do tratamento foram mais uniformemente distribuídas. Embora a negligência também tenha sido a razão mais apresentada, foi logo sucedida pela falta de cuidado, que se apresentou de maneira mais frequente do que no caso do paciente negro. Seguindo uma ordem decrescente, teve-se a higiene do paciente e a não cooperação. Assim como no caso do paciente negro, algumas respostas indicaram que a responsabilidade seria do paciente, mas sem apresentar justificativa para isso. Ainda, um menor número de respostas referiu-se a outras questôes, como condiçôes de saúde bucal do paciente e hábitos deletérios. 
Tabela 2. Atribuição da responsabilidade pelo insucesso do tratamento por cor/raça do paciente. Florianópolis, 2017

\begin{tabular}{|c|c|c|}
\hline \multirow{2}{*}{$\begin{array}{l}\text { Atribuição de } \\
\text { Responsabilidade }\end{array}$} & \multicolumn{2}{|c|}{ Cor/raça } \\
\hline & $\begin{array}{c}\text { Paciente negro } \\
\text { N (\%) }\end{array}$ & $\begin{array}{c}\text { Paciente branco } \\
\text { N (\%) }\end{array}$ \\
\hline Paciente e profissional & $69(41,57)$ & $77(46,38)$ \\
\hline Paciente & $42(25,30)$ & $27(16,26)$ \\
\hline Profissional & $37(22,29)$ & $41(24,70)$ \\
\hline Não atribuiu responsabilidade & $4(2,410)$ & $2(1,20)$ \\
\hline Náo especificou ou responsabilizou outros fatores & $12(7,22)$ & $17(10,24)$ \\
\hline Não soube responder & $02(1,20)$ & $02(1,20)$ \\
\hline Total & $166(100,00)$ & $166(100,00)$ \\
\hline
\end{tabular}

Fonte: elaboração própria.

Quadro 2. Exemplos de justificativas relacionadas à atribuiçẫo de responsabilidade pelo insucesso do tratamento ao paciente negro e ao paciente branco por categorias temáticas, em ordem decrescente de frequência. Florianópolis, 2017

\begin{tabular}{|c|c|c|}
\hline \multirow{7}{*}{ 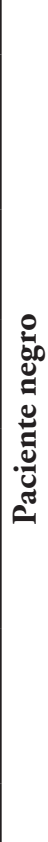 } & Justificativas & Exemplos de respostas \\
\hline & Negligência & $\begin{array}{l}\text { "Paciente, pelo fato de negligenciar certas informações fornecidas por mim." } \\
\text { "O paciente, pois após ter concordado com a conduta de tratamento, ele } \\
\text { não seguiu as recomendaçôes pós-operatórias." }\end{array}$ \\
\hline & $\begin{array}{l}\text { Não } \\
\text { cooperação }\end{array}$ & "Para que o tratamento ocorra, é necessária a cooperação do paciente." \\
\hline & $\begin{array}{l}\text { Sem } \\
\text { justificativa }\end{array}$ & "Se as orientaçōes foram devidamente passadas, a culpa é do paciente." \\
\hline & $\begin{array}{l}\text { Falta de } \\
\text { higiene }\end{array}$ & $\begin{array}{l}\text { "Se tudo correu bem no tratamento, o culpado é o paciente por falta de } \\
\text { higiene. Pois um bom tratamento não depende apenas do profissional, } \\
\text { mas também dos cuidados pós-operatórios do paciente." } \\
\text { "Paciente, higiene oral péssima!" }\end{array}$ \\
\hline & $\begin{array}{l}\text { Falta de } \\
\text { cuidado }\end{array}$ & $\begin{array}{l}\text { "Cuidados inapropriados (paciente)". } \\
\text { "Se o procedimento foi bem executado e o paciente não teve os devidos } \\
\text { cuidados, ele é o responsável pelo insucesso." }\end{array}$ \\
\hline & Outros & "Se o paciente continuar com seus hábitos, também irá fracassar." \\
\hline
\end{tabular}

continua... 


\begin{tabular}{|c|c|c|}
\hline \multirow{7}{*}{ 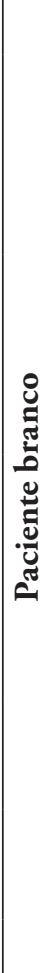 } & Justificativas & Exemplos de respostas \\
\hline & Negligência & $\begin{array}{l}\text { "Não seguiu as recomendaçóes pós-operatórias prescritas pelo CD.” } \\
\text { "O paciente também tem de seguir as orientaçôes pós-tratamento, } \\
\text { dependendo de qual tipo de insucesso, o CD tem o respaldo legal para } \\
\text { atribuir a responsabilidade do insucesso ao paciente." }\end{array}$ \\
\hline & $\begin{array}{l}\text { Falta de } \\
\text { cuidado }\end{array}$ & $\begin{array}{l}\text { "Falta de cuidado do paciente." } \\
\text { "No caso de exodontia, poderá acontecer inflamação dos tecidos, } \\
\text { que está diretamente relacionada com os cuidados pós-operatórios do } \\
\text { paciente." }\end{array}$ \\
\hline & $\begin{array}{l}\text { Falta de } \\
\text { higiene }\end{array}$ & $\begin{array}{l}\text { "Se o tratamento foi acordado por ambos, o paciente assume a } \\
\text { responsabilidade de cuidar da higiene, o que é imprescindível para } \\
\text { garantir o sucesso do tratamento." } \\
\text { "Avaliando as condiçóes bucais deste paciente, eu diria que foi a falta de } \\
\text { higiene oral. [...]." }\end{array}$ \\
\hline & $\begin{array}{l}\text { Não } \\
\text { cooperação }\end{array}$ & "O paciente, caso ele não seja colaborativo." \\
\hline & $\begin{array}{l}\text { Sem } \\
\text { justificativa }\end{array}$ & "O paciente deve compreender os riscos do tratamento antes de iniciá-lo." \\
\hline & Outros & "Estado geral da saúde bucal do paciente." \\
\hline
\end{tabular}

Quando as respostas dadas aos pacientes hipotéticos (tanto o paciente negro quanto o branco) citaram o dentista (quadro 3) como responsável pelo insucesso do tratamento, a justificativa mais frequente foi relacionada à técnica. Porém, quando o paciente hipotético era branco, a técnica foi usada de maneira mais recorrente como justificativa do que quando o paciente era negro. Na sequência, apresentamse as justificativas que indicavam o planejamento inadequado e as recomendaçôes inadequadas. No caso do paciente negro, o planejamento inadequado como razão para falha no sucesso do tratamento foi uma explicação mais recorrente do que falha nas recomendaçôes de cuidados pós-tratamento passadas aos pacientes. Por sua vez, no caso do paciente branco, ambas as justificativas foram presentes de maneira semelhante. A má conduta do profissional também foi citada, incluindo as respostas que não especificaram em que momento do contato com o paciente essa conduta foi falha. O diagnóstico e o acompanhamento inadequados foram outras duas razóes pelas quais o dentista foi considerado responsável pelo insucesso do 
tratamento, porém, se destacando menos do que as outras razóes. Respostas sem justificativas também foram recorrentes, em ambos os casos, sendo mais presentes em relação ao paciente branco.

Quadro 3. Exemplos de respostas relacionadas à atribuiçẫo de responsabilidade pelo insucesso do tratamento ao profissional em relaçáo às justificativas apontadas. Florianópolis, 2017

\begin{tabular}{|c|c|}
\hline Justificativas & Exemplos de respostas \\
\hline Técnica & $\begin{array}{l}\text { "Profissional deve ter executado algum passo do tratamento } \\
\text { incorretamente." } \\
\text { "Eu dentista, pois pode ter invadido o espaço biológico ou a raiz não } \\
\text { era satisfatória para o tratamento escolhido." }\end{array}$ \\
\hline Planejamento & $\begin{array}{l}\text { "O profissional, por não ter escolhido a melhor opção de tratamento." } \\
\text { "Profissional, antes de dar início a qualquer tratamento temos que } \\
\text { adequar e mudar hábitos de higiene. Mesmo a manutenção sendo } \\
\text { feita pelo paciente, o profissional só deve começar o tratamento } \\
\text { restaurador e protético após a adequação." }\end{array}$ \\
\hline Recomendações & $\begin{array}{l}\text { "Possivelmente faltou recomendaçóes mais claras da parte do } \\
\text { profissional para a manutençáo do tratamento [...]." } \\
\text { "Eu, por não ter esclarecido/convencido o paciente de que ele precisa } \\
\text { mudar seus hábitos." }\end{array}$ \\
\hline Má conduta & $\begin{array}{l}\text { "O profissional pode ter negligenciado alguma coisa." "O dentista } \\
\text { que não ficou atento." }\end{array}$ \\
\hline Diagnóstico & $\begin{array}{l}\text { "O dentista, pois provavelmente não foram observadas e levadas em } \\
\text { conta o real estado do paciente, isto é, sua real necessidade (tratar a } \\
\text { causa da doença/problema)." } \\
\text { "Minha responsabilidade por não ter avaliado o paciente de forma } \\
\text { correta e ter adequado seu tratamento ao seu estilo e dificuldades de } \\
\text { vida." }\end{array}$ \\
\hline Acompanhamento & $\begin{array}{l}\text { "Do profissional por deixar de acompanhar o caso com maior } \\
\text { frequência e por deixar de relembrar informaçóes de cuidados." } \\
\text { "Principalmente o dentista, o qual deveria manter retornos frequentes } \\
\text { do paciente, já que este era de risco." }\end{array}$ \\
\hline
\end{tabular}

Fonte: elaboração própria. 


\section{Discussão}

Estudo prévio com os mesmos casos clínicos não obteve resultados estatisticamente significativos de que a decisão por extrair ou restaurar um elemento dental estava associada com a cor/raça do paciente hipotético (SCHROEDER et al., 2017). A presente análise, portanto, objetivou complementar e aprofundar o estudo da questão por meio do exame das respostas abertas dos participantes a outras perguntas contidas no questionário utilizado no estudo. Tais itens faziam alusão a situaçóes potencialmente conflitivas entre paciente e profissional e solicitavam o respondente a se posicionar, englobando desde aspectos de discordância sobre o tratamento proposto até a condição de insucesso do tratamento executado.

Em relação a como os estudantes procederiam, caso o paciente náo concordasse com o tratamento, houve uma quantidade expressiva de respostas que consideraram menos a opiniáo e a expectativa dos pacientes (41,9\%), para ambos os pacientes branco e negro. Os participantes atribuíram ao paciente negro mais respostas de cunho paternalista e se mostraram menos receptivos à sua autonomia. Este achado é ainda mais importante se considerarmos que a cor/raça era a única diferença existente, uma vez que o caso clínico foi, rigorosamente, o mesmo. Respeitar a autonomia do indivíduo implica perceber a capacidade e o direito de o mesmo de se governar, buscando compreender suas razóes e objetivos. Atribuir maior ou menor autonomia em função de características sociais pode refletir uma recomendação de caráter discriminatório, a qual deve ser problematizada em meio à formação e atuação profissional (CROCHIC; MASSOLA; SVARTMAN, 2015). Modelos alternativos - como o de "decisão participativa", em que o profissional propóe e orienta o paciente, estimulando-o a tomar decisões (UGARTE; ACIOLY, 2014), bem como a ferramenta de "clínica ampliada e compartilhada" (BRASIL, 2012), que considera a subjetividade e individualidade do sujeito juntamente com a complexidade do processo saúde-doença - são recursos que enriquecem e qualificam o diagnóstico e os diálogos em direção à maior autonomia dos usuários.

Ao analisar os resultados da segunda pergunta, quando os estudantes foram questionados a respeito do insucesso do tratamento, as respostas, em sua grande maioria (89,16\% para pacientes negros e $87,34 \%$ para pacientes brancos), consideraram o paciente e/ou o profissional como responsáveis pelo insucesso. Ao analisar exclusivamente a responsabilidade do paciente, os negros foram mais 
frequentemente responsabilizados. Embora a análise de conteúdo não tenha evidenciado diferentes justificativas atribuídas às respostas que responsabilizaram o paciente branco ou o negro, notou-se que, para o paciente branco, a "falta de cuidado" esteve mais presente do que "não cooperação" para o negro. As justificativas relacionaram-se principalmente às falhas nos deveres de ambos perante o tratamento, rotineiramente desconsiderando todos os demais fatores, como reaçóes do organismo, falhas de material, mas, sobretudo, os fatores socialmente determinantes, o que gera uma preocupação acerca da compreensão do fenômeno saúde-doença por parte dos estudantes.

Em outras palavras, pensar no insucesso de procedimentos na assistência à saúde de modo mais restrito ("higiene ineficiente" ou "negligência do paciente") significa secundarizar toda a carga de interferências sociais nos processos de saúde-doença. A perspectiva verticalizada da relação profissional-paciente, em que o primeiro é o único responsável pelas decisóes clínicas e o paciente tem suas questôes silenciadas, é própria de um modelo de atuação no qual "saberes" éticos e humanizadores são pontuais e desconectados da vivência profissional (REGO; GOMES; SIQUEIRABATISTA, 2008). Além disso, as justificativas também evidenciam, ainda que de forma indireta, uma possível naturalização do tratamento desigual entre brancos e negros, uma vez que estes últimos podem ter menos autonomia.

Quando questôes discriminatórias não são problematizadas na formação em saúde, tem-se profissionais pouco reflexivos e que visualizam o outro como instrumento ou objeto, e não atores sociais capazes de questionar as estruturas sociais e contribuir para sua transformaçâo. Todavia, para que essa nova forma de saber seja gerada, é necessário não somente educação dos discentes, mas formação continuada do corpo docente e de todos que trabalham dentro das instituiçóes de ensino. A discussão torna-se ainda mais delicada quando consideramos que, para a formação profissional em saúde, é fundamental haver o contato com os indivíduos (FINKLER; CAETANO; RAMOS, 2013; UGARTE; ACIOLY, 2014), de forma que atender a esses princípios com efetividade a partir de uma metodologia de ensino baseada no cientificismo e na concepção flexneriana da formação em saúde hegemônica é um tanto paradoxal.

A partir disso, consideram-se necessárias - e até já estão ocorrendo, lentamente reformulaçóes no processo de formação em saúde (COTTA et al., 2007), fomentando o desenvolvimento de profissionais capazes de dialogar com a sociedade e de discutir 
e repensar práticas humanizadas e humanizadoras. Tais práticas são necessárias para que mantenham o respeito à subjetividade e autonomia das pessoas e, enquanto estudantes, estes consigam conciliar o interesse acadêmico com a necessidade do paciente-sem priorizar um em detrimento do outro - e, como profissionais, consigam buscar os princípios norteadores do Sistema Único de Saúde, principalmente a equidade e a universalidade (FINKLER; CAETANO; RAMOS, 2013).

Isto implica mudanças nas perspectivas do corpo docente em relação às necessidades dos saberes dentro da universidade. É fundamental que aqueles que ensinam reflitam e desenvolvam competência crítica capaz de discutir problemas e dificuldades sociais - incluindo as particularidades que o próprio ensino em saúde possui - resgatando a importância de lições que vão além de conhecimentos teóricos e práticos, mas que abrangem todas as relaçóes sociais que se desenvolvem no processo de ensino e aprendizagem (FINKLER; CAETANO; RAMOS, 2011; 2013). Assuntos (bio)éticos e relativos à humanização devem ser abordados de modo transversal na formação do profissional em saúde, entendendo que é tarefa de todos os professores instigar nos alunos a reflexão sobre tais temas, abordandoos ao longo da aprendizagem teórico-prática. Assim, eles não seriam elementos extrínsecos à vivência do profissional, mas parte fundamental da reflexão de toda e qualquer situação pela qual este mesmo profissional irá passar (REGO; GOMES; SIQUEIRA-BATISTA, 2008).

As reflexôes acadêmicas são fundamentais para a desconstrução do racismo, causador de desigualdades nos serviços, nos benefícios e, consequentemente, nas oportunidades, mas precisam ser associadas às políticas de "desracialização". Esses instrumentos se complementam na medida em que o saber e o desenvolvimento de conteúdo acadêmico sirvam de instrumento de investigação e fortalecimento de políticas públicas que aumentem a equidade da sociedade (LOPEZ, 2012). Nesse sentido, temos como exemplo políticas de açôes afirmativas, incluindo o sistema de cotas, que pôs as portas da universidade um pouco mais próximas dos negros, indígenas e pobres e permitiu maior representatividade de grupos sociais marginalizados no meio acadêmico. Essa representatividade resulta em criação de espaços de voz e reflexão, como os coletivos e grupos universitários a respeito do tema. No âmbito da saúde, existe a Política Nacional de Saúde Integral da População Negra, que reconhece e diagnostica o racismo institucional e o preconceito étnicoracial nas instituiçôes de saúde, a fim de combatê-los, instruindo movimentos 
sociais, profissionais e gestores em saúde para prover saúde de melhor qualidade para a população negra (BRASIL, 2013).

Os resultados obtidos com o presente estudo sugerem a atribuição de menor autonomia a pacientes hipotéticos negros, relativamente aos brancos, bem como de maior frequência de responsabilização daqueles pelos casos de insucesso clínico do tratamento. Recomenda-se a realização de mais pesquisas para compreender se e como tais diferenças se transformam em condutas profissionais de caráter discriminatório, de modo que os futuros profissionais de Odontologia não reproduzam ou intensifiquem as desigualdades raciais que atravessam diferentes dimensôes da sociedade brasileira. ${ }^{1}$

\section{Referências}

BASTOS, J. L.; CELESTE, R. K.; PARADIES, Y. C. Racial Inequalities in Oral Health. Journal of Dental Research, v. 97, n. 8, p. 878-886, Jul 2018.

BRASIL. Ministério da Saúde. Secretaria de Atenção à Saúde. Politica Nacional de Humanização. Brasília: Ministério da Saúde, 2012.

. Ministério da Saúde. Secretaria de Gestáo Estratégica e Participativa. Departamento de Apoio à Gestão Participativa Política nacional de saúde integral da população negra: uma política do SUS. Brasília: Ministério da Saúde, 2013.

. Ministério da Saúde. Secretaria de Gestão Estratégica e Participativa. Departamento de Articulação Interfederativa. Temático Saúde da População Negra. Painel de Indicadores do SUS. Brasília, v. 7, p. 81, 2016.

CABRAL, E. D.; CALDAS JR, A. F.; CABRAL, H. A. Influence of the patient's race on the dentist's decision to extract or retain a decayed tooth. Community Dentistry and Oral Epidemiology, v. 33, n. 6, p. 461-6, Dec 2005.

COTTA, R. M. M. et al. Pobreza, injustiça, e desigualdade social: repensando a formação de profissionais de saúde. Revista Brasileira de Educação Médica, v. 31, n. 3, p. 278-286, 2007.

CROCHIC, J. L.; MASSOLA, G. M.; SVARTMAN, B. P. A ideologia do cientificismo. Psicologia USP, v. 26, n. 1, p. 10-22, 2015.

DONATO, C. R. Plano Juventude Viva: caminhos da política de prevenção à violência contra a juventude negra no Brasil. Brasília: Secretaria Geral da Presidência da República, 2014.

FINKLER, M.; CAETANO, J. C.; RAMOS, F. R. S. A dimensão ética da formação profissional em saúde: estudo de caso com cursos de graduaçáo em Odontologia. Ciência \& Saúde Coletiva, v. 16, n. 11, p. 4481-4492, 2011. 
FINKLER, M.; CAETANO, J. C.; RAMOS, F. R. S. Ética e valores na formação profissional em saúde: um estudo de caso. Ciência \& Saúde Coletiva, v. 18, n. 10, p. 3033-3042, 2013.

FREITAS, S. F. T. et al. Stages of Moral development among Brazilian dental students. Journal of Dental Education, v. 70, n. 3, p. 296-306, 2006.

FREITAS, S. F. T. D.; KOVALESKI, D. F.; BOING, A. F. Desenvolvimento moral em formandos de um curso de Odontologia: uma avaliação construtivista. Ciência \& Saúde Coletiva, v. 10, n. 2, p. 453-462, 2005.

GONÇALVES, E. R.; VERDI, M. I. M. Os problemas éticos no atendimento a pacientes na clínica odontológica de ensino. Ciência \& Saúde Coletiva, v. 12, n. 3, p. 755-764, 2007.

GRACIA, D. El juramento hipocratico. In: . (Ed.). Como arqueros al blanco: estudios de bioética. Madrid: Triacastela, 2004. p. 245-263.

INSTITUTO BRASILEIRO DE GEOGRAFIA E ESTATÍSTICA. Sintese de indicadores sociais: uma análise das condiçóes de vida da população brasileira. Rio de Janeiro: IBGE, 2016. LOPEZ, L. C. O conceito de racismo institucional: aplicaçóes no campo da saúde. Interface: Comunicação, educação e saúde, v. 16, n. 40, p. 121-134, 2012.

MINAYO, M. C. D. S. O desafio do conhecimento: metodologia de pesquisa social (qualitativa) em saúde. 14. Rio de Janeiro: Fiocruz, 2014.

REGO, S.; GOMES, A. P.; SIQUEIRA-BATISTA, R. Bioética e humanização como temas transversais na formação médica. Revista Brasileira de Educação Médica, v. 32, n. 4, p. 482-491, 2008. SCHROEDER, F. C. et al. To extract or to restore the tooth? Color/race and clinical decision making among undergraduate dental students from Southern Brazil. Pesquisa Brasileira em Odontopediatria e Clínica Integrada, v. 17, n. 1, p. e3700, 2017.

SEYFERTH, G. Colonização, imigração e a questão racial no Brasil. Revista USP, v. 53, n. 117-149, 2002.

TELLES, E. E. Demography of race in Brazil. In: SAENZ, R.; EMBRICK, D. et al. (Ed.). International Handbook of the Demography of Race and Ethnicity. New York: Springer, 2016. p. 151-170.

Race in another America: the significance of skin color in Brazil. Princeton: Princeton University Press, 2004.

THE NATIONAL COMMISSION FOR THE PROTECTION OF HUMAN SUBJECTS OF BIOMEDICAL AND BEHAVIORAL RESEARCH. The Belmont Report: ethical principles and guidelines for the protection of human subjects of research. Government Printing Office. Washington, D.C., 1979.

UGARTE, O. N.; ACIOLY, M. A. O princípio da autonomia no Brasil: discutir é preciso... Revista do Colégio Brasileiro de Cirurgióes, v. 41, n. 5, p. 374-377, 2014. 


\section{Nota}

${ }^{1}$ L. C. Candido realizou a revisão de literatura, análise dos dados e redação da primeira versão completa do manuscrito. M. Finkler participou da concepção do estudo, supervisão da análise dos dados, redação parcial e revisão da versão final do artigo. J. L. Bastos participou da concepção do estudo, coleta de dados, redação parcial e revisão final do texto. S. F. T. de Freitas participou da concepção do estudo, análise dos dados, redação parcial e revisão final do artigo. 


\section{Abstract}

\section{Conflicts with the patient, race and} conceptions held by Dental students: The case of undergraduates from Southern Brazil

The socio-historical processes that occurred in Brazil resulted in health inequalities between different ethnic and racial groups. This study aimed to assess whether the conceptions held by Dental students vary according to the patient's race, when a hypothetic patient disagrees with the proposed treatment, as well as when the treatment fails. Data were collected with a self-completed questionnaire, which was administered to 166 undergraduate students living in Southern Brazil. The questionnaire was presented with a hypothetical clinical scenario on two different occasions; in the first one, the patient was black and, in the second one, white. On both occasions, the case asked about treatment decisions of a similarly affected tooth, after which the respondent had to answer some open-ended items. The answers were analyzed with Thematic Content Analysis. Results suggest a less respectful behavior towards and less autonomy given to the black patient, as compared with the white one. Black patients were also more responsible for treatment failures as compared to their white peers. Based on these results, we suggest that the training of health professionals should focus on the issue of racial inequalities, to better equip them to build a less unequal society.

> Keywords: health services; professional education; higher education; oral health. 